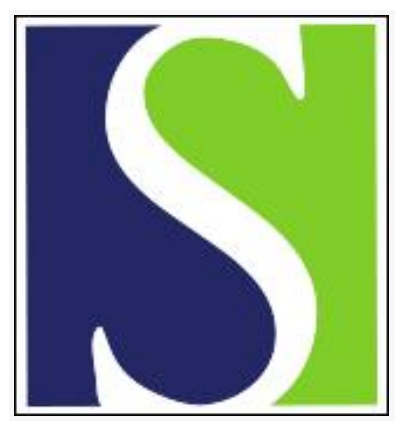

Scand J Work Environ Health 2005;31(1):52-58

https://doi.org/10.5271/sjweh.848

Issue date: Feb 2005

Nasal mucosal histamine reactivity among teachers six years after working in a moisture-damaged school

by Rudblad S, Andersson K, Bodin L, Stridh G, Juto J-E

Affiliation: Department of Otorhinolaryngology, Örebro University Hospital, SE-701 85 Örebro, Sweden. stig.rudblad@orebroll.se

The following article refers to this text: SJWEH Supplements 2008;(4):35-38

Key terms: histamine provocation; histamine reactivity; laser-doppler flowmetry; longitudinal study; microcircular perfusion; moisture damage; mucosal swelling; nasal mucus; nose; rhinostereometry; school; teacher

This article in PubMed: www.ncbi.nlm.nih.gov/pubmed/15751619 


\title{
Nasal mucosal histamine reactivity among teachers six years after working in a moisture-damaged school
}

\author{
by Stig Rudblad, MD, ${ }^{1}$ Kjell Andersson, MD, ${ }^{2}$ Lennart Bodin, PhD, ${ }^{3}$ Göran Stridh, PhD, ${ }^{2}$ Jan-Erik Juto, MD ${ }^{4}$
}

\begin{abstract}
Rudblad S, Andersson K, Bodin L, Stridh G, Juto J-E. Nasal mucosal histamine reactivity among teachers six years after working in a moisture-damaged school. Scand J Work Environ Health 2005;31(1):52-58.
\end{abstract}

\begin{abstract}
Objectives The objective of this study was to determine whether verified increased nasal mucosal reactivity among teachers, who had been working in a school with severe moisture problems, still persisted 6 years after remedial measures had been taken. The increased nasal mucosal reactivity, measured as the mucosal swelling reaction upon histamine provocation, had earlier been shown both 1 and 3 years after the renovation.

Methods Twenty-four teachers in the target school and sixteen teachers in the control school, who participated in all the investigations (1995, 1997 and 2000), answered a standardized questionnaire and underwent a nasal histamine provocation test. In addition to the registration of mucosal swelling, the microcircular reaction to histamine provocation was measured with laser-Doppler flowmetry.

Results The nasal histamine reactivity among the teachers, measured as the mucosal swelling reaction, was no longer increased. However, the laser-Doppler flowmetry showed that the teachers in the target school had significantly divergent microcircular perfusion $(\mathrm{P}=0.0022)$ and a concentration of moving blood cells $(\mathrm{P}=0.0009)$ in the histamine provocation when compared with the teachers in the control school; this finding indicates morepronounced plasma leakage and edema from the nasal mucosa.

Conclusions Restored nasal histamine reactivity, measured as mucosal swelling reaction, was observed among the teachers 6 years after an obviously successful renovation of the school environment. However, changes in microcirculation indicate a remaining effect on the nasal mucosa.
\end{abstract}

Key terms histamine provocation; laser-Doppler flowmetry; longitudinal study; microcircular perfusion; mucosal swelling; rhinostereometry.

It has been shown that building dampness and mold exposure are associated with an increase in respiratory symptoms (1-3). Sensitive methods have been developed for studying nasal mucosal reactivity (ie, acoustic rhinometry and rhinostereometry) $(4,5)$. These methods are not invasive and are well tolerated by the persons investigated.

With the combination of rhinostereometry and laserDoppler flowmetry, it has been possible to measure congestion and microcirculatory patterns of the nasal mucosa simultaneously $(6,7)$.

In 1995 (ie, 1 year after extensive remedial measures had been taken in a water-damaged school) a random sample of the teachers $(\mathrm{N}=28)$ who had worked in the water-damaged school for at least 5 years before the renovation were exposed to a nasal histamine provocation test and compared with teachers $(\mathrm{N}=18)$ from a control school with previous ventilation problems but without moisture problems (8).

Technical investigations of the target school before the renovation showed severe dampness because of inadequate drainage and numerous water leaks from the roof causing growth of molds in the building construction and decomposition and discoloring of the building materials. Renovation in the target school was directed towards the water-damage and included replacement of damaged building materials, reconstruction of the drainage system, and removal of wall-to-wall carpets.

A significantly increased reaction (ie, nasal mucosal swelling) to histamine provocation was found among

1 Department of Otorhinolaryngology, Örebro University Hospital, Örebro, Sweden.

2 Department of Occupational and Environmental Medicine, Örebro University Hospital, Örebro, Sweden.

3 Unit of Biostatistics and Epidemiology, Clinical Research Center, Örebro University Hospital, Örebro, Sweden.

4 Department of Otorhinolaryngology, Huddinge University Hospital, Huddinge, Sweden.

Reprint requests to: Dr Stig Rudblad, Department of Otorhinolaryngology, Örebro University Hospital, SE-701 85 Örebro, Sweden [E-mail: stig.rudblad@orebroll.se] 
the teachers in the school with previous moisture problems. In 1997, a follow-up study showed that there was still a significant difference in nasal histamine reactivity between the teachers in the two schools, although there was a decrease in reactivity among the teachers in the target school (9).

The aim of this study was to determine whether the increased nasal reactivity to histamine measured in 1995 among the teachers in the target school still persisted 5 years later (ie, 6 years after remedial measures had been taken). In addition to mucosal swelling as a measure of mucosal reactivity, the microcircular reaction of the nasal mucosa to histamine provocation with laser-Doppler flowmetry was measured. The purpose was to see if there was a difference in this respect between the two teacher groups and also if there was a correlation between mucosal swelling and measured microcirculation. The study had been approved by the Ethics Committee of the Örebro County Council.

\section{Study population and methods}

\section{Methodology}

The nasal histamine provocation tests in 1995 were performed at the hospital using a single-blind design, and the investigator was not given details about the workplace of the teachers. In 1997 and 2000 the provocations were carried out in an identical manner in the respective schools (9). In 2000 the teachers were also exposed to laser-Doppler flowmetry in order to study the microcirculation of the nasal mucosa.

\section{Study population}

In 1995 a random sample of teachers, who had worked at least 5 years in the target school before the renovation (39 persons), and all teachers in the control school who fulfilled the same inclusion criteria (30 persons) were invited to participate in the study. Twenty-eight and eighteen teachers, respectively, gave their informed consent and formed the two study groups (8). In 1997, 26 and 18 teachers from the target and control schools, respectively, participated (9). All the teachers from the study in 1995 (8), except one from the target school and one from the control school who had died, were invited in 2000 to participate (27 and 17 from the target and control schools, respectively). Twenty-four teachers from the target school and sixteen from the control school agreed to participate and formed the two study groups who participated on all three occasions. The reason for nonparticipation was mainly lack of time or no longer working at the school. All three investigations were performed in early spring (March and April).

\section{Questionnaires}

During the period of acclimatization, before the histamine provocation, the same standardized questionnaire as that administered in 1995 and 1997 was answered (MM 040 NA) (10). The questionnaires are widely used (eg, in the Nordic countries) for studying respondents' perception of the quality of indoor air and workplace condition, as well as their symptoms of sick building syndrome attributed to the work environment $(11,12)$.

\section{Skin-prick test}

In 1995 all teachers underwent a standardized skin-prick test $(8,13)$. Skin-prick test positivity (SPT+) was defined as the formation of a wheal with a diameter of at least 3 millimeters in response to any of the allergens used. Eighteen and seventeen percent of the teachers in the target and the control schools, respectively, had a positive test.

\section{Provocation test}

A standardized nasal provocation procedure, as described by Hallén \& Juto (14), was used with a histamine solution in three concentrations (1, 2 and $4 \mathrm{mg} / \mathrm{ml})$. The histamine solution was applied through a self-retaining nasal speculum with a syringe on the medial side of the right inferior conchae. The provocation was started with the lowest histamine concentration $(1 \mathrm{mg} / \mathrm{ml})$. Recordings of the mucosal swelling, on the provoked side, were made with rhinostereometry before and 2, 5, and 10 minutes after the first and lowest histamine concentration $(1 \mathrm{mg} / \mathrm{ml})$ and 5 and 10 minutes after provocation with the two higher histamine concentrations ( 2 and $4 \mathrm{mg} / \mathrm{ml})(15)$.

Laser-Doppler flowmetry is a noninvasive method for studying microcirculation, and it has the advantage of giving continuous and instantaneous measures of the nasal mucosa blood flow (6). It was performed using a Periflux 4001 (Perimed, Sweden). We used a specially designed micromanipulator-guided probe for the flowmetry measurements. It was positioned approximately 0.3 millimeters from the medial surface of the inferior turbinate (16). A rhinostereometer equipped with the micromanipulator (Rhinomed, Sweden) was used to combine laser-Doppler flowmetry and rhinostereometry. The microcircular parameters, the concentration of moving blood cells (CMBC), the velocity of blood flow (VU) and their product, the perfusion of flow (PU), were recorded. The recordings were done before and 2 and 5 minutes after the lowest histamine concentrations and 5 minutes after the provocation with the two higher histamine concentrations. Because of the lack of calibrations against other methods for measuring blood flow 
in the specific tissue, the data have been expressed in arbitrary units and as deviations from the baseline. The measurements register the microcirculation to a depth of more than 1 millimeter in the tissue but above the big venous vessels, the sinusoids. The measurements were recorded on a personal computer with special software (PeriSoft for Windows, version 1.10)

\section{Statistical analyses}

Analyses of complaints, symptoms, and mucosal swelling over the three observation occasions, as well as perfusion and $\mathrm{CMBC}$, were done with methods for repeated measurements. Different models were used depending on the distributional properties of the outcome variables.

The prevalence of complaints and symptoms was analyzed with a generalized linear model analogous to a logistic regression model but with allowance for correlated responses for the three occasions. The outcome parameter was the odds ratio for the prevalence of the complaints and symptoms. The explanatory factors in this model were school (two levels: target and control), observation year (three levels: 1995, 1997, and 2000), and the interaction between school and year.

The continuous outcomes of mucosal swelling, perfusion, and CMBC were also analyzed with a generalized linear model, but in this case the model was analogous to an analysis of variance (ANOVA) model with repeated measurements. For mucosal swelling there were up to seven explanatory variables included in the model [ie, school, year and histamine dose level (three levels: $1 \mathrm{mg} / \mathrm{ml}, 2 \mathrm{mg} / \mathrm{ml}$ and $4 \mathrm{mg} / \mathrm{ml}$ )] and interactions between two of these factors, as well as the threefactor interaction. A potential explanatory factor, time after provocation with two levels, 5 and 10 minutes, was not introduced into the model but handled through a separate analysis for each time point.

For perfusion and $\mathrm{CMBC}$, we had observations only from 2000. The model could therefore be simplified by excluding the factor year. Otherwise the statistical model was similar to the one used for mucosal swelling. In an additional analysis of perfusion and $\mathrm{CMBC}$, our interest was not the effect of dose, but rather the effect of time after provocation. In this experiment, dose was fixed at $1 \mathrm{mg} / \mathrm{ml}$, and readings were done at 2,5 , and 10 minutes after the provocation. The statistical model was similar to the previous model, but, instead of the factor dose, we used the factor time (with three levels: 2, 5, and 10 minutes) and the interaction between school and time.

The ANOVA was first done with all the interactions included, followed by a sequential search for parsimonious models in which interactions of no statistical significance were excluded. Evaluations of the goodness- of-fit of the models were done with Akaike's information index (17).

When a final ANOVA model had been found, we tried to describe the basic shape of the provocation curves (the response variable modeled as a function of dose or time) by slightly reformulating the model. In this model, we estimated the linear regression of an increase in swelling per ${ }^{2} \log \mathrm{mg} / \mathrm{ml}$ histamine (doses 1,2 , and 4 $\mathrm{mg} / \mathrm{ml}$ which give the logarithmic values 0,1 and 2) for each school. We also determined the $95 \%$ confidence intervals $(95 \% \mathrm{CI})$ for the estimates of the intercept and slope in these regressions. This linear model was also used in the analysis of perfusion and CMBC with dose. For these outcomes, we also analyzed the effect of time with a linear regression. Time was then set at 2, 5, and 10 , that is, the actual times recorded.

Correlation coefficients for the linear association within and between swelling, perfusion, and CMBC (measured with different dose and time levels) were calculated according to Pearson's and Spearman's correlation coefficients.

Our analytical models were implemented with SAS and BMPD statistical packages [SAS version 8.1 (modules GENMOD and MIXED, SAS Institute Inc., Cary, $\mathrm{NC}$, USA) and BMPD version 7 (procedure 5V, BMPD Inc, Los Angeles, CA, USA)].

\section{Results}

\section{Reported complaints and symptoms}

As shown in table 1, there were more complaints of varying and low room temperatures among the teachers in the target school than among the teachers in the control school. The analysis of varying room temperature and low room temperature showed a significant difference between the two schools $(\mathrm{P}=0.01$ and $\mathrm{P}=0.04$, respectively). The odds ratios for complaints, with the control school teachers as referents, were 5.7 (95\% CI 1.2-27.7) and 5.4 (95\% CI 1.1-25.6), respectively, indicating a much higher risk for complaints at the target school.

For poor indoor-air quality there was also a significant difference between the two schools $(\mathrm{P}=0.01)$, and the odds ratio was 5.3 (95\% CI 1.2-22.3) for the target school, but no significance for the factor year or the interaction school $\times$ year (ie, the relation between the two schools was stable during the years of the investigations).

For the symptoms none of the investigated factors (ie, difference between schools, difference between years and interaction school $\times$ year) showed statistical significance. 


\section{Provocation test}

Rhinostereometry and mucosal swelling. Table 2 shows the mean swelling of the nasal mucosa provoked with increasing histamine concentrations. The ANOVA showed that in 1995 the teachers in the two schools had a statistically significant difference in their response to increased provocation levels $(\mathrm{P}=0.001$ for the 5 -minute readings). In 1997, the difference had decreased, but when compared with the 1995 values, the difference was still statistically significant. In 2000 there were no statistically significant differences. The linear regression analysis of mucosal swelling in table 3 illustrates the estimates of the intercepts, slopes, and $95 \%$ confidence intervals of the provocation curves of the teachers when they underwent repeated histamine provocation. The response to the provocation levels, and how this response slowly converges from 1995 to 2000 to almost the same values for the teachers in the two schools, is clearly seen from the slope estimates. For the target school, the slopes go from 0.46 to 0.28 to 0.23 , and for the control school they are $0.15,0.21$, and 0.18 , respectively, according to the values from the 5-minute readings.

Figure 1 shows the gradually decreasing difference between the histamine provocation curves of the two teacher groups. The swelling reaction 2 minutes (in 2000) after the provocation with the lowest histamine concentration was more pronounced in the two study groups than after 5 or 10 minutes (figure 1c)

\section{Laser-Doppler flowmetry}

An analysis of variance of repeated measurements of perfusion for various dose levels according to school, on the basis of the 5-minute readings, showed a significant difference for school $\times$ dose $(\mathrm{P}=0.0022)$ and indicated a difference in reaction patterns between the two
Table 1. Prevalence of complaints and symptoms in the target and control schools in 1995, 1997, and 2000.

\begin{tabular}{|c|c|c|c|c|c|c|}
\hline \multirow[t]{2}{*}{ Complaints } & \multicolumn{3}{|c|}{ Target school $(\mathrm{N}=24)$} & \multicolumn{3}{|c|}{ Control school $(\mathrm{N}=16)$} \\
\hline & $\begin{array}{l}\text { Total } \\
\text { number } \\
\text { of } \\
\text { responses } \\
\text { (N) }\end{array}$ & $\begin{array}{l}\text { Res- } \\
\text { ponded } \\
\text { "yes" } \\
\text { (N) }\end{array}$ & $\%$ & $\begin{array}{l}\text { Total } \\
\text { number } \\
\text { of } \\
\text { responses } \\
\text { (N) }\end{array}$ & $\begin{array}{l}\text { Res- } \\
\text { ponded } \\
\text { "yes" } \\
\text { (N) }\end{array}$ & $\%$ \\
\hline
\end{tabular}

\begin{tabular}{|c|c|c|c|c|c|c|}
\hline \multicolumn{7}{|c|}{ Air quality } \\
\hline \multicolumn{7}{|c|}{ Varying room-temperature } \\
\hline 1995 & 23 & 5 & 21.7 & 16 & 0 & 0.0 \\
\hline 1997 & 22 & 9 & 40.9 & 15 & 2 & 13.3 \\
\hline 2000 & 20 & 5 & 25.0 & 14 & 1 & 7.1 \\
\hline \multicolumn{7}{|c|}{ Low room-temperature } \\
\hline 1995 & 24 & 1 & 4.2 & 16 & 0 & 0.0 \\
\hline 1997 & 22 & 7 & 31.8 & 16 & 1 & 6.3 \\
\hline 2000 & 20 & 5 & 25.0 & 15 & 1 & 6.7 \\
\hline \multicolumn{7}{|c|}{ Poor indoor air quality a } \\
\hline 1995 & 24 & 13 & 54.2 & 16 & 2 & 12.5 \\
\hline 1997 & 24 & 8 & 33.3 & 16 & 2 & 12.5 \\
\hline 2000 & 24 & 10 & 41.7 & 16 & 2 & 12.5 \\
\hline \multicolumn{7}{|c|}{ Symptoms } \\
\hline \multicolumn{7}{|c|}{ General symptoms ${ }^{b}$} \\
\hline 1995 & 24 & 12 & 50.0 & 16 & 7 & 43.8 \\
\hline 1997 & 24 & 10 & 41.7 & 16 & 8 & 50.0 \\
\hline 2000 & 24 & 8 & 33.3 & 16 & 7 & 43.8 \\
\hline \multicolumn{7}{|c|}{ Mucosal irritative symptoms ${ }^{c}$} \\
\hline 1995 & 24 & 7 & 29.2 & 16 & 3 & 18.8 \\
\hline 1997 & 24 & 8 & 33.3 & 16 & 1 & 6.3 \\
\hline 2000 & 24 & 4 & 16.7 & 16 & 3 & 18.8 \\
\hline \multicolumn{7}{|c|}{ Skin symptoms $^{d}$} \\
\hline 1995 & 24 & 5 & 20.8 & 16 & 3 & 18.8 \\
\hline 1997 & 24 & 3 & 12.5 & 16 & 3 & 18.8 \\
\hline 2000 & 24 & 2 & 8.3 & 16 & 3 & 18.8 \\
\hline \multicolumn{7}{|c|}{$\begin{array}{l}\text { a Percentage of teachers often troubled (= at least every week) by stuffy } \\
\text { bad air, dry air, or an unpleasant smell in the preceding 3-month } \\
\text { period. } \\
\text { b Frequency of teachers often troubled by tiredness, feeling heavy- } \\
\text { headedness, headache, nausea, vertigo, or concentration problems. } \\
\text { ' Frequency of teachers often troubled by irritated eyes, nose, throat, or } \\
\text { cough. } \\
\text { d Frequency of teachers often troubled by facial dryness or redness, } \\
\text { scaly and itchy scalp, or ears, or dry and itchy skin on the hands } \\
\text { (eczema of the hands). }\end{array}$} \\
\hline
\end{tabular}

Table 2. Mean swelling of the mucosal membrane in the nose for different levels of histamine among the participants who were present at all the examinations. Recordings at 5 and 10 minutes after the provocation.

\begin{tabular}{|c|c|c|c|c|c|c|c|c|c|c|c|c|}
\hline \multirow[t]{4}{*}{ School } & \multicolumn{12}{|c|}{ Histamine level } \\
\hline & \multicolumn{4}{|c|}{$1 \mathrm{mg} / \mathrm{ml}$} & \multicolumn{4}{|c|}{$2 \mathrm{mg} / \mathrm{ml}$} & \multicolumn{4}{|c|}{$4 \mathrm{mg} / \mathrm{ml}$} \\
\hline & \multicolumn{2}{|c|}{$5 \min$} & \multicolumn{2}{|c|}{$10 \mathrm{~min}$} & \multicolumn{2}{|c|}{$5 \mathrm{~min}$} & \multicolumn{2}{|c|}{$10 \mathrm{~min}$} & \multicolumn{2}{|c|}{$5 \mathrm{~min}$} & \multicolumn{2}{|c|}{$10 \mathrm{~min}$} \\
\hline & Mean (mm) & SD & Mean (mm) & $\mathrm{SD}$ & Mean (mm) & SD & Mean (mm) & SD & Mean (mm) & SD & Mean (mm) & SD \\
\hline \multicolumn{13}{|c|}{ Target $(\mathrm{N}=24)$} \\
\hline 1995 & 0.48 & 0.79 & 0.49 & 0.79 & 1.00 & 0.87 & 0.90 & 0.90 & 1.42 & 0.88 & 1.05 & 0.89 \\
\hline 1997 & 0.70 & 0.66 & 0.44 & 0.68 & 1.01 & 0.84 & 0.77 & 0.82 & 1.27 & 0.86 & 1.02 & 0.83 \\
\hline 2000 & 0.60 & 0.44 & 0.56 & 0.50 & 0.95 & 0.54 & 0.91 & 0.56 & 1.14 & 0.59 & 1.03 & 0.64 \\
\hline \multicolumn{13}{|c|}{ Control (N=16) } \\
\hline 1995 & 0.53 & 0.56 & 0.44 & 0.53 & 0.88 & 0.79 & 0.69 & 0.70 & 0.89 & 0.77 & 0.62 & 0.65 \\
\hline 1997 & 0.45 & 0.22 & 0.30 & 0.28 & 0.71 & 0.38 & 0.54 & 0.38 & 0.89 & 0.40 & 0.68 & 0.34 \\
\hline 2000 & 0.51 & 0.36 & 0.44 & 0.37 & 0.89 & 0.35 & 0.79 & 0.35 & 1.00 & 0.39 & 0.87 & 0.44 \\
\hline
\end{tabular}


Table 3. Linear regression analysis of mucosal swelling induced by histamine provocation (logarithmic values 0,1 , and 2 ) stratified for time after provocation, year, and school.

\begin{tabular}{llllll}
\hline \multirow{2}{*}{ Time } & \multicolumn{2}{c}{ Intercept } & & \multicolumn{2}{c}{ Slope } \\
\cline { 5 - 6 } \cline { 5 - 6 } & Estimate & $95 \% \mathrm{Cl}$ & & Estimate & $95 \% \mathrm{Cl}$ \\
\hline 5 minutes & & & & \\
1995 & & & & \\
$\quad$ Target school & 0.46 & $0.19-0.73$ & & 0.46 & $0.35-0.58$ \\
$\quad$ Control school & 0.43 & $0.11-0.76$ & & 0.15 & $0.01-0.30$ \\
1997 & & & & \\
$\quad$ Target school & 0.68 & $0.48-0.88$ & & 0.28 & $0.19-0.36$ \\
$\quad$ Control school & 0.43 & $0.18-0.68$ & & 0.21 & $0.11-0.31$ \\
2000 & & & & \\
$\quad$ Target school & 0.61 & $0.45-0.77$ & & 0.23 & $0.17-0.30$ \\
$\quad$ Control school & 0.54 & $0.35-0.74$ & & 0.18 & $0.11-0.26$ \\
10 minutes & & & & \\
1995 & & & & \\
$\quad$ Target school & 0.48 & $0.21-0.75$ & & 0.29 & $0.18-0.39$ \\
$\quad$ Control school & 0.43 & $0.09-0.76$ & & 0.10 & $-0.03-0.23$ \\
1997 & & & & \\
$\quad$ Target school & 0.44 & $0.22-0.66$ & & 0.28 & $21-0.35$ \\
$\quad$ Control school & 0.30 & $0.03-0.35$ & 0.17 & $0.09-0.26$ \\
2000 & & & & \\
Target school & 0.63 & $0.46-0.80$ & 0.20 & $0.13-0.27$ \\
Control school & 0.53 & $0.32-0.74$ & 0.17 & $0.08-0.25$ \\
\hline
\end{tabular}
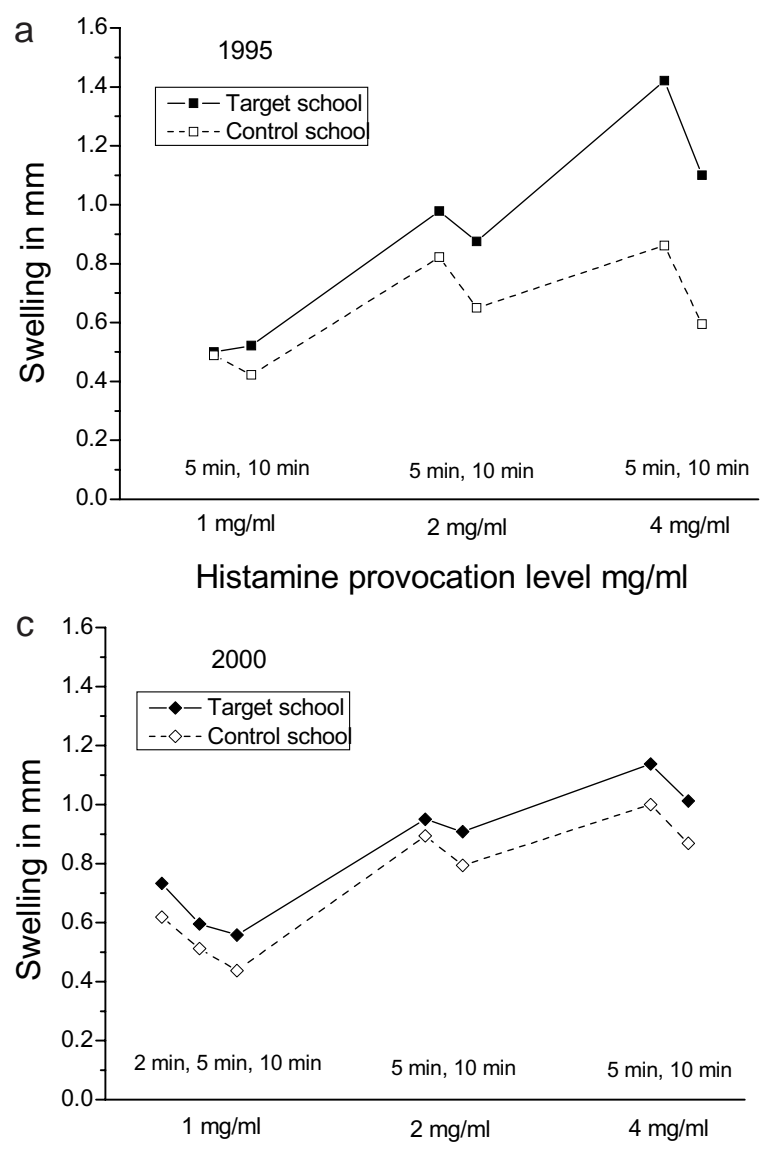

Histamine provocation level $\mathrm{mg} / \mathrm{ml}$ teacher groups during the provocation procedure. This result is well illustrated in figure $2 \mathrm{a}$, where the microcircular perfusion in the nasal mucosa steeply increases from the 2-minute baseline value after the first provocation with the lowest histamine concentration in the two teacher groups. The control group then seems to restore the level of perfusion rapidly and reacts more strongly to the following provocations when compared with the weaker reaction from the teachers in the target school. There was also a significant difference over time $(2,5$, and 10 minutes $)(\mathrm{P}=0.0064)$ when the lowest histamine concentration $(1 \mathrm{mg} / \mathrm{ml})$ was considered.

Figure $2 b$ shows the changes in CMBC during the histamine provocation procedure. The teachers in the target school, in contrast to those in the control school, showed a decrease in their CMBC after the first histamine provocation, and the value remained low during the whole provocation procedure. There was a significant difference based on the 5-minute readings for the factor school $(\mathrm{P}=0.0009)$, but not for the factor school $\times$ dose $(\mathrm{P}=0.25)$; this finding indicates that the provocation curves were well separated, with a similar reaction pattern during the provocation procedure. As with perfusion, there was also a significant difference over time

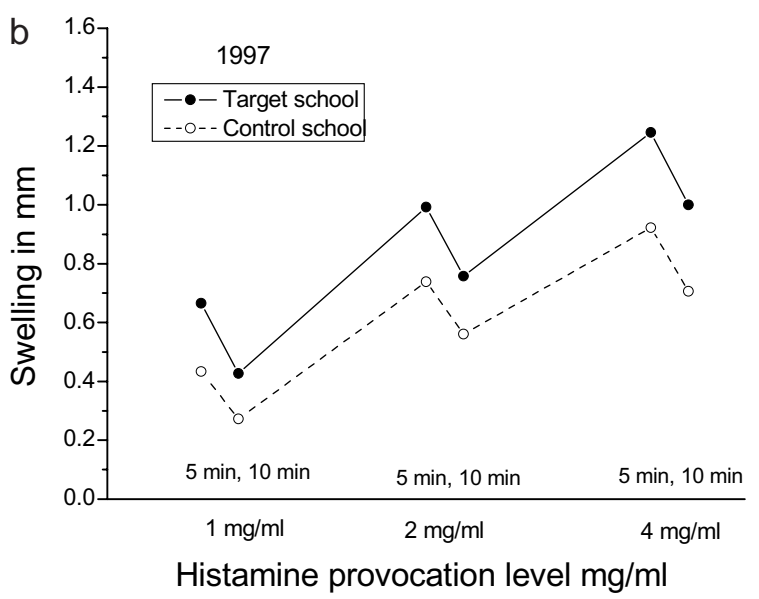

Figure 1. Histamine provocation curves (the mean net change in mucosal swelling from the baseline values) for teachers from the target and control schools, as measured on three occasions, in 1995, 1997, and 2000. 

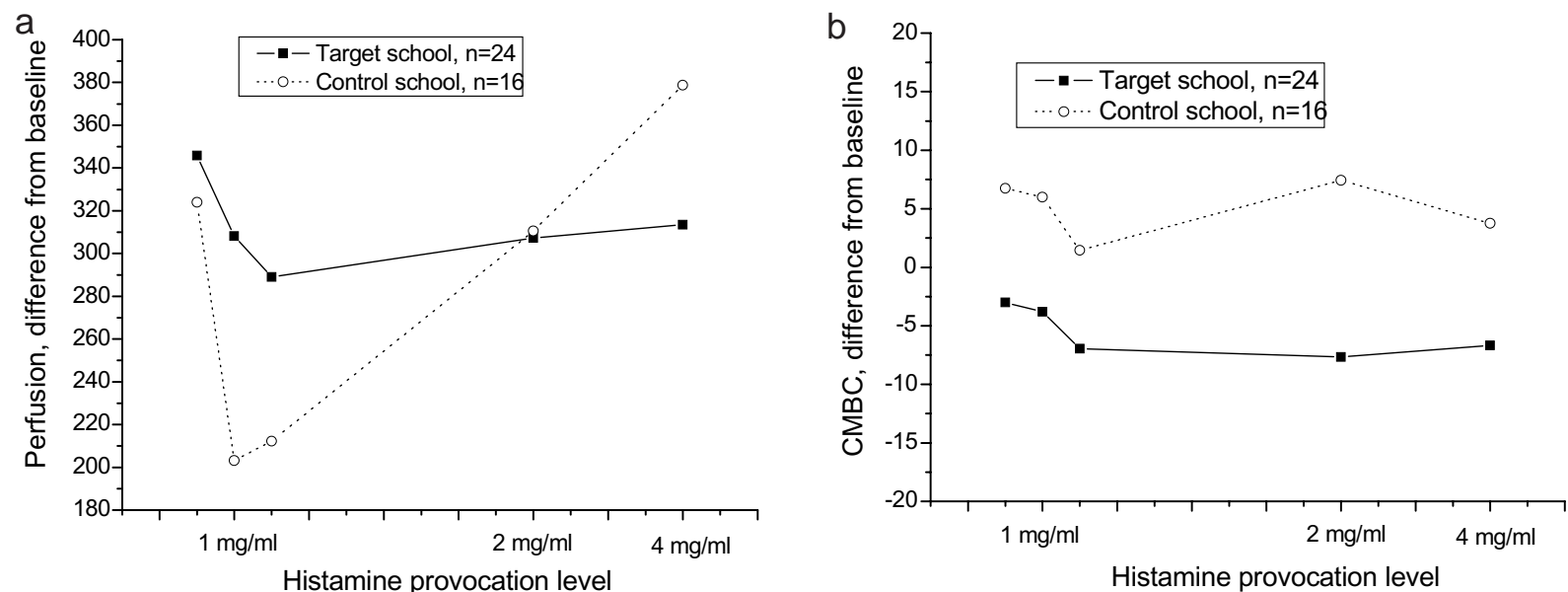

Figure 2. Difference from the baseline values for perfusion and the concentration of moving blood cells (CMBC). Values read at 2, 5, and 10 minutes after histamine provocation at the $1 \mathrm{mg} / \mathrm{ml}$ level and at 5 minutes for the 2 and $4 \mathrm{mg} / \mathrm{ml}$ levels.

$(\mathrm{P}=0.0048)$ when the lowest histamine concentration was considered.

There was no correlation between measured mucosal swelling and laser-Doppler flowmetry (perfusion and $\mathrm{CMBC}$ values) during the histamine provocation procedure, the correlation coefficients almost all being on the order of -0.10 to 0.10 .

\section{Discussion}

The statistical analyses showed no significant differences regarding nasal histamine reactivity, measured as the mucosal swelling reaction, between the teachers in the target school and those in the control school 6 years after remedial measures had been taken. We interpret the results, in combination with the outcome of the intermediate study in 1997 (9), as an indication that longterm exposure to building dampness increases the risk for nasal mucosal hyperreactivity, which only slowly decreases over the years after the indoor environment has been restored. The cause of this mucosal hyperreactivity is unclear but may depend on exposure to different chemical or microbial emissions from constructions of the moisture-damaged building; this possibility is not easily determinable using our current methods of measurement $(18,19)$. The reason for this prolonged increased reactivity, even after remedial measures have been taken, is probably an ongoing physiological restoring process in the mucosa of the upper airways.

In conformity with another study (20), we also found that the maximal swelling reaction upon provocation with the lowest histamine concentration occurred in both groups as early as after 2 minutes. This fact encouraged us to consider the 5- and 10-minute reactions as essentially quite different, and therefore handled them separately in the statistical analyses.
The high frequency of the perception of poor indoor air among the teachers in the target school in 1995 only marginally decreased during the years of observation. This phenomenon may have something to do with the difficulty to maintain a uniform temperature in a single-story building, and this lack of uniformity then leading to a significantly higher prevalence of complaints of varying and low room temperature among the target school teachers. Uniformity of temperature and welladapted ventilation are important for comfort and seem to be associated with a lower incidence of perceived air dryness (21), which was a dominating complaint in the perception of poor indoor air climate among the target school teachers $(8,9)$.

The frequency of reported mucosal irritative symptoms and skin symptoms decreased among the teachers in the target school during the time of observation. However, there were no statistically significant differences regarding these symptoms over time between the teachers in the two schools, probably because the study was not fully dimensioned to evaluate differences in these parameters.

Upon repeated histamine provocation, the nasal microcircular flow (perfusion) of the teachers in the target school showed a slower reaction pattern with a flatter provocation curve than that of the teachers in the control group. This slow reaction may correlate with a leakage of plasma from the capillaries in the mucosa, followed by interstitial edema.

The CMBC is probably affected by changes in the amount of interstitial fluid (22). The flatter perfusion curve and the decreasing CMBC during the histamine provocations among the teachers at the target school strongly indicate an increased tendency for plasma leakage and interstitial edema. Hence, although there were no significant differences between the two study groups regarding nasal mucosal swelling upon histamine provocation, there still seems to be a difference in 
the superficial microcircular pattern. This fact indicates that long-term exposure to building dampness may do more damage to the superficial subepitelial layer of the nasal mucosa and is followed by a longer restoring process than that of the deeper structures. Accordingly, the absence of correlations between mucosal congestion and the microcircular pattern upon histamine provocation probably depends on the fact that rhinostereometry measures mucosal congestion due to dilatation of the deeper situated sinusoids in the nasal mucosa, whereas laser-Doppler flowmetry measures the superficial microcircular pattern (6).

In conclusion, we found restored nasal histamine reactivity, measured as mucosal swelling reaction, among the teachers 6 years after long-term exposure to building dampness.

We also found remaining changes in the microcircular pattern in this teacher group when it was compared with the control group.

\section{Acknowledgments}

The study received financial support from the Research Committee of the Örebro County Council. It was also supported by grants from the Swedish Working Life Research Fund.

Research assistant Inger Fagerlund at the Department of Occupational and Environmental Medicine, Örebro University Hospital, Örebro, Sweden, assisted with the provocation tests and the computer analysis of the data.

\section{References}

1. Nafstad P, Oie L, Gaarder PI, Lodrup-Carlseb KC, Botten G, Magnus $\mathrm{P}$, et al. Residential dampness problems and symptoms and signs of bronchial obstruction in young Norwegian children. Am J Respir Crit Care Med 1998;157:410-4.

2. Peat JK, Dickerson J, Li J. Effects of damp and mould in the home on respiratory health: a review of the literature. Allergy 1998;53:120-8

3. Taskinen T, Hyvärinen A, Meklin T, Husman T, Nevalainen A, Korppi M. Asthma and respiratory infections in school children with special reference to moisture problems in the school. Acta Paedriatr 1999;88:1373-9.

4. Hilberg O. Objective measurement of nasal airway dimensions using acoustic rhinometry: methodological and clinical aspects. Allergy 2002;57 Suppl 70:5-39.

5. Graf P, Hallen H. Clinical and rhinostereometric assessment of nasal mucosal swelling during histamine challenge. Clin Otolaryngol 1996;21:72-5.

6. Grudemo H, Juto JE. Rhinostereometry and laser doppler flowmetry in human nasal mucosa: changes in congestion and microcirculation during intranasal histamine challenge. ORL J Otolaryngol Relat Spec 1997;59:50-6.

7. Grudemo H, Juto JE. Studies of spontaneous fluctuations in congestion and nasal mucosal microcirculation and the effects of oxymetazoline using rhinostereometry and micromanipulator guided laser-doppler flowmetry. Am J Rhinol 1999;13:16.

8. Rudblad S, Andersson K, Juto JE, Bodin L. Nasal hyperreactivity among teachers in a school with a long history of moisture problems. Am J Rhinol 2001;15:135-41.

9. Rudblad S, Andersson K, Stridh G, Bodin L, Juto JE. Slowly decreasing mucosal hyperreactivity years after working in a school with moisture problems. Indoor Air 2002;12:138-44.

10. Andersson K. Epidemiological approach to indoor air problems. Indoor Air 1998;Suppl 4:32-9.

11. Reijula K, Sundman-Digert C. Assessment of indoor air problems at work with a questionnaire. Occup Environ Med 2004;61:33-8.

12. Lahtinen M, Sundman-Digert C, Reijula K. Psychosocial work environment and indoor air problems: a questionnaire as a means of problem diagnosis. Occup Environ Med 2004;61:143-9.

13. Dreborg S. The skin prick test: methodological studies and clinical applications [dissertation]. Linköping (Sweden): University of Linköping; 1987. p 1-148. Medical dissertation, no 239.

14. Hallén H, Juto JE. A test for objective diagnosis of nasal hyperreactivity. Rhinology 1993;31:23-5.

15. Juto JE, Lundberg C. An optical method for determining changes in mucosal congestion in the nose in man. Acta Otolaryngol 1982;94:149-56.

16. Grudemo H, Juto JE. The impact of the measuring distance on laser-doppler measurements of the microcirculation in human nasal mucosa. ORL J Otolaryngol Relat Spec 1997;59:280-5.

17. Akaike H. Information theory and an extension of the maximum likelihood principle. In: Petrov EBN, Csaki F, editors. 2nd International Symposium on Information Theory and Control. Budapest: Akademia Kiado; 1973. p 267-81.

18. Claesson AS, Levin JO, Blomqvist G, Sunesson AL. Volatile metabolites from Microorganisms grown on humid building materials and synthetic media. J Environ Monit 2002;4:66772.

19. Wieslander G, Norback D, Nordström K, Walinder R, Venge P. Nasal and ocular symptoms, tear film stability and biomarkers in nasal lavage, in relation to building-dampness and building design in hospitals. Int Arch Occup Environ Health 1999;72:451-61.

20. Grudemo H, Juto JE. Intranasal histamine challenge in normal subjects and allergic rhinitis before and after intranasal budesonide studied with rhinostereometry and micromanipulatorguided laser Doppler flowmetry. ORL J Otorhinolaryngol Relat Spec 2000;62:33-8.

21. Jalas J, Karjalainen K, Kimari P. Indoor air and energy economy in school buildings. In: Finnish Society of Indoor Air and Climate/ISIAQ. Proceedings of Healthy Buildings 2000: vol 4. Espoo (Finland): Finnish Society of Indoor Air Quality and Climate/ISIAQ; 2000. p 273-8.

22. Grudemo H, Juto JE. The effect of saline-induced edema in the human nasal mucosa on laser Doppler flowmetry. Rhinology 1999;37:104-7.

Received for publication: 19 December 2003 